\title{
Fontan conversion to total cavopulmonary connection and arrhythmia ablation: clinical and functional results
}

\author{
G Agnoletti, A Borghi, G Vignati, G C Crupi
}

Heart 2003;89:193-198

See end of article for authors' affiliations

Correspondence to: Dr Gabriella Agnoletti, Service de Cardiologie Pédiatrique, Necker Enfants Malades, 149, rue de Sevres, 75743 Paris

Cedex, France;

gabriella.agnoletti@

nck.ap-hop-paris.fr

Accepted

2 October 2002

\begin{abstract}
Objectives: To assess the early results of conversion from atriopulmonary to total cavopulmonary connection in patients with failing Fontan operation.

Design: Early clinical and instrumental evaluation of patients undergoing conversion from atriopulmonary to total cavopulmonary connection from April 1999 to November 2000.

Setting: Tertiary referral centre for congenital heart disease.

Patients: 11 Fontan patients (mean (SD) age 20.9 (6.7) years) with refractory arrhythmias or ventricular dysfunction.

Interventions: Total cavopulmonary connection, intraoperative ablation, and AAIR pacemaker implantation.

Main outcome measures: Holter monitoring, transoesophageal atrial stimulation, ergometric test, and myocardial scintigraphy at a mean (SD) follow up of $16.8(5.6)$ months.

Results: One early postoperative death occurred. During follow up three patients had relapse of atrial tachycardia, controlled by medical treatment, and two were pacemaker dependent. Transoesophageal stimulation did not induce atrial tachycardia in any patient. Ergometric test showed a diminished exercise tolerance in all but one patient. Mean minute ventilation and maximum oxygen consumption were $62 \%$ and $40 \%$ of their respective predicted values. Myocardial scintigraphy showed reversal of rest or exercise dysfunction in five patients and improved systemic ventricular function in seven. Mean basal ejection fraction increased from $39.4 \%(95 \%$ confidence interval $(\mathrm{Cl}) 32 \%$ to $46 \%$ ) to $46.5 \% 195 \% \mathrm{Cl}$ $41.7 \%$ to $51.2 \%$ ) and ejection fraction on effort from $42.3 \%(95 \% \mathrm{Cl} 33.9 \%$ to $50.7 \%)$ to $50.2 \%(95 \%$ Cl $44.5 \%$ to $55.9 \%$ ).

Conclusions: Our data show that total cavopulmonary connection associated with intraoperative ablation and pacemaker implantation allows for better control of arrhythmias and improves ventricular function in the majority of patients with failing Fontan.
\end{abstract}

F ontan operation, first introduced in $1971,{ }^{1}$ has undergone several modifications aimed at diminishing or relieving right atrial enlargement and avoiding the presence of slow, turbulent systemic venous flow, which are the usual late effects of the classic Fontan operation. ${ }^{2-7}$ It is known that patients undergoing the Fontan operation can develop several complications caused by right atrial enlargement, increased systemic venous pressure, and slow, turbulent venous flow, such as atrial arrhythmias, compression of the right pulmonary veins, coronary sinus hypertension, atrial thrombi, and pulmonary embolism. ${ }^{8-11}$ These complications can, in turn, have grave consequences; thus, arrhythmias can lead to myocardial failure and development of atrial thrombi, pulmonary vein compression can cause low cardiac output and pulmonary hypertension, and coronary sinus hypertension can induce myocardial impairment. All these possible events make the late Fontan patient a complex patient, often difficult to treat either medically or surgically.

The present practice of total cavopulmonary connection, introduced in 1990 by Marcelletti, ${ }^{6}$ excludes the right atrium from the systemic venous circuit, preserves a laminar systemic venous flow, and is expected to decrease the incidence of atrial arrhythmias and myocardial impairment.

Recently, conversion from atriopulmonary to total extracardiac cavopulmonary connection has been shown to improve myocardial function and functional class and to control refractory arrhythmias in most patients. ${ }^{12}{ }^{13}$ Whether this operation should be routinely associated with antiarrhythmic atrial procedures such as atrial cryoablation or radiofrequency ablation and atrial pacemaker implantation is still being debated.
From April 1999 to November 2000, 11 patients had conversion of atriopulmonary anastomosis to total cavopulmonary connection associated with antiarrhythmic procedures. We review this experience.

\section{METHODS}

\section{Patient population}

There were six male and five female patients. The mean (SD) age at reoperation was 20.9 (6.7) years. The mean (SD) time interval between initial Fontan and total cavopulmonary connection was 15.6 (2.5) years. All patients had first time conversion. One patient (patient 7) with double inlet left ventricle and discordant ventriculoarterial junction had atriopulmonary anastomosis and resection of subaortic stenosis.

Table 1 lists the clinical characteristics of the patients, including primary diagnoses, previous Fontan connection, New York Heart Association (NYHA) functional class, and type and onset of arrhythmias. Table 2 lists the haemodynamic data.

Indications for reoperation were as follows.

- Functional class higher than II-four patients were in class III and one (patient 9) developed transient congestive heart failure during atrial arrhythmia.

- Debilitating atrial arrhythmias-eight patients had intraatrial re-entry tachycardia and two suffered from episodes of atrial fibrillation. Medical treatment was partially or completely ineffective in six and three patients, respectively. Endocardial radiofrequency ablation had been attempted, without success, in two patients ( 3 and 6 ), and two ( 5 and 9) required multiple cardioversions. Two patients with atrial 
Table 1 Clinical characteristics of the patients

\begin{tabular}{|c|c|c|c|c|c|c|c|c|}
\hline Patient & $\begin{array}{l}\text { Age at repeat } \\
\text { Fontan (years) }\end{array}$ & Diagnosis & $\begin{array}{l}\text { Age at initial } \\
\text { Fontan (years) }\end{array}$ & Type of initial Fontan & $\begin{array}{l}\text { Years from } \\
\text { last Fontan }\end{array}$ & $\begin{array}{l}\text { NYHA } \\
\text { class }\end{array}$ & $\begin{array}{l}\text { Type of } \\
\text { arrhythmia }\end{array}$ & $\begin{array}{l}\text { Onset of arrhythmia } \\
\text { (years after Fontan) }\end{array}$ \\
\hline 1 & 18 & DILV & 4 & Direct atriopulmonary & 14 & II & $\mathrm{AF}$ & 13 \\
\hline 2 & 18 & TA & 3.5 & Direct atriopulmonary & 14.5 & ॥ & AT & 10 \\
\hline 3 & 12 & TA & 2.5 & Direct atriopulmonary & 9.5 & III & AT & 1 \\
\hline 4 & 25 & TA & 21 & Homograft No 21 & 18 & ॥ & None & NA \\
\hline 5 & 36 & DILV & 22 & Direct atriopulmonary & 14 & ॥ & $\mathrm{AF}$ & 13 \\
\hline 6 & 24 & TA & 7.5 & Direct atriopulmonary & 17 & ॥ & AT & 13 \\
\hline 7 & 15 & DILV & 3.2 & Direct atriopulmonary & 12 & II & AT & 3 \\
\hline 8 & 23 & TA & 5 & Pericardium roofed & 18 & III & AT & 16 \\
\hline 9 & 17 & TA & 3.5 & Direct atriopulmonary & 13 & ॥ & Af & 13 \\
\hline 10 & 21 & TA & 4 & Direct atriopulmonary & 17 & III & $\mathrm{AF}$ & 2 \\
\hline 11 & 25 & TA & 5.5 & Dacron roofed & 20 & III & AT, SSS & 1 \\
\hline
\end{tabular}

Af, atrial fibrillation; AF, atrial flutter; AT, atrial tachycardia; DILV, double inlet left ventricle; NA, not applicable; NYHA, New York Heart Association; SSS, sick sinus syndrome; TA, tricuspid atresia.

fibrillation were symptomatic for syncope (10) and congestive heart failure (9). At time of repeat Fontan nine patients were in sinus rhythm, one had junctional rhythm (10), one had chronic atrial tachycardia (8).

- Anatomical obstruction-one patient had obstruction at the atriopulmonary junction caused by calcification of the homograph, with a peak gradient of $13 \mathrm{~mm} \mathrm{Hg}$.

- Severe ventricular dysfunction-the majority of patients had ventricular dysfunction at rest, shown by echocardiography or scintigraphy; five had ventricular dysfunction on effort.

Thus, the primary indications for repeat Fontan were debilitating arrhythmias in seven patients, anatomical obstruction in one, ventricular dysfunction in five, and coexistence of more than one indication in three. Preoperative analysis of arrhythmias consisted of Holter monitoring and, when possible, an ergometric test. Electrophysiological study was not performed either preoperatively or intraoperatively, as it was not considered to be useful.

Statistical evaluation was performed with paired Student's $t$ test.

\section{Operative procedure}

All patients had right atriopulmonary anastomosis .The operative technique has been previously described. ${ }^{6}{ }^{12}$ After preparation of the femoral vessels and median sternotomy, the right atrium, the superior and inferior venae cavae, and the atriopulmonary anastomosis were widely dissected and the pulmonary branches mobilised. Aortobicaval cardiopulmonary bypass and moderate hypothermia $\left(32^{\circ} \mathrm{C}\right)$ were used. During cooling a longitudinal right atriotomy was performed so as to achieve adequate exposure of the atriopulmonary anastomosis. The superior and inferior venae cavae and the atriopulmonary anastomosis were divided and a generous right atrial reduction was performed with concomitant excision of the right appendage. Early in our experience, atrial septectomy was performed before intraoperative treatment of arrhythmias and as a consequence the duration of the aortic cross clamping time was longer. In the last four patients arrhythmias were treated intraoperatively before atrial septectomy on a beating heart with much shorter duration of the aortic cross clamp, which was limited to the atrial septectomy and suture of the right atriotomy. With the exception of one patient in whom induced ventricular fibrillation was used, the aortic cross clamp was removed only when the right atrial incisions were sutured. Air was evacuated from the left atrium and ventricle in a routine fashion.

Intraoperative treatment of arrhythmias included cryoablation (Frigitronics, Shelton, Connecticut, USA) in six patients and radiofrequency ablation (Thermaline Boston Scientific, San Jose, California, USA) in five. The same surgical approach was used regardless of the type of arrhythmias. When cryoablation was used, multiple lesions $\left(-60^{\circ}\right.$ for 90 seconds each) were placed in linear fashion between the coronary sinus and the atrioventricular valve anulus, the coronary sinus and the inferior vena cava, the inferior vena cava and the atrioventricular valve annulus, the atriopulmonary anastomosis and the superior vena cava, and along the atrial septum, following the procedure illustrated by Mavroudis and colleagues. ${ }^{12}$ Similar linear lesions were performed with radiofrequency multipolar catheter $\left(60^{\circ}\right.$ for 90 seconds each).

The right pulmonary artery was incised and a superior cavopulmonary connection was fashioned, placing the anastomosis towards the bifurcation. The inferior aspect of the right pulmonary artery was then incised and an inferior cavopulmonary connection was created by interposition of a PTFE (polytetrafluoroethylene) conduit. The diameter of the conduit was $22 \mathrm{~mm}$ in 10 patients and $24 \mathrm{~mm}$ in the last patient. In the first two patients an atrial pacemaker lead was placed in

Table 2 Haemodynamic data

\begin{tabular}{ccllll}
\hline Patient & CVP $(\mathrm{mm} \mathrm{Hg})$ & Atriomegaly & $\begin{array}{l}\text { Incompetence of } \\
\text { atrioventricular valve }\end{array}$ & EF (\%) & Associated problems \\
\hline 1 & 8 & Moderate & Moderate to severe & 30 & Slow systemic venous flow, incompetent pulmonary stump \\
2 & 10 & Moderate & Moderate & 50 & MAPCAs, slow systemic venous flow \\
3 & 15 & Severe & None & 50 & Slow systemic venous flow \\
4 & 20 & Moderate & None & 50 & Calcified obstructed conduit, venous collaterals \\
5 & 7 & Moderate & Moderate & 50 & Slow systemic venous flow, aortic incompetence, MAPCAs \\
6 & 8 & Severe & Mild to moderate & $>50$ & Slow systemic venous flow \\
7 & 12 & Moderate & None & $>50$ & Slow systemic venous flow, aneurism of the outflow chamber \\
8 & 8 & Moderate & None & $>50$ & LSV to CS, severe dilatation of CS, slow systemic venous flow \\
9 & 12 & Severe & None & Slow systemic venous flow \\
10 & 18 & Severe & Mild to moderate & 50 & Slow systemic venous flow \\
11 & 16 & Moderate & Severe & Slow systemic venous flow, venous collaterals \\
\hline
\end{tabular}

CS, coronary sinus; CVP, central venous pressure; EF, ejection fraction; LSVC, left superior vena cava; MAPCAs, aortopulmonary collaterals. 


\begin{tabular}{|c|c|c|c|c|c|c|c|c|c|c|}
\hline Patient & $\begin{array}{l}\text { Conduit } \\
\text { size }(\mathrm{mm})\end{array}$ & Type of ablation & $\begin{array}{l}\text { ECC } \\
\text { (hours) }\end{array}$ & $\begin{array}{l}\text { Aortic cross } \\
\text { clamp time } \\
\text { (min) }\end{array}$ & $\begin{array}{l}\text { Mechanical } \\
\text { ventilation } \\
\text { (days) }\end{array}$ & $\begin{array}{l}\text { ICU stay } \\
\text { (days) }\end{array}$ & $\begin{array}{l}\text { Hospital } \\
\text { stay (days) }\end{array}$ & Complications & $\begin{array}{l}\text { ECG rhythm } \\
\text { at discharge }\end{array}$ & Outcome \\
\hline 1 & 22 & Cryoablation & 6 & 30 & 2 & 5 & 21 & None & SR & Well \\
\hline 2 & 22 & Cryoablation & 4.5 & 50 & 2 & 4 & 20 & None & SR & Well \\
\hline 3 & 22 & Cryoablation & 9.5 & 90 & 2 & 4 & 18 & None & PM & Well \\
\hline 4 & 22 & Cryoablation & 8.5 & 22 & 3 & 5 & 16 & None & SR & Well \\
\hline 5 & 22 & Cryoablation & 8.5 & None & 11 & 11 & NA & Pneumonia & NA & Died \\
\hline 6 & 24 & Cryoablation & 7.5 & 34 & 2 & 2 & 14 & None & SR/PM & Well \\
\hline 7 & 22 & RFA & 7.5 & 65 & 2 & 5 & 18 & None & PM & Well \\
\hline 8 & 22 & RFA & 8.6 & 15 & 3 & 7 & 22 & None & SR & Well \\
\hline 9 & 24 & RFA & 10.7 & 19 & 1 & 2 & 36 & Limb ischaemia & PM & Well \\
\hline 10 & 24 & RFA & 8.5 & 15 & 1 & 3 & 30 & $\begin{array}{l}\text { Low output } \\
\text { syndrome }\end{array}$ & PM & Well \\
\hline 11 & 22 & RFA & 6.2 & 14 & 0.5 & 2 & 25 & None & PM & Well \\
\hline
\end{tabular}

ECC, extracorporeal circulation; ICU, intensive care unit; PM, pacemaker; RFA, radiofrequency ablation; SR, sinus rhythm.

the left atrium according to the technique of Hoyer and colleagues $^{14}$; in the remaining patients an eluting steroid epicardial lead was used. In nine patients the lead was connected to a pacemaker implanted in a subfascial abdominal pouch.

The only patient receiving associated procedures (patient 7) had patch exclusion of a right ventricular aneurysm.

\section{Follow up}

All patients were assessed with echocardiography, Holter monitoring, transoesophageal stimulation, ergometric test with oxygen consumption, and myocardial scintigraphy.

Echocardiography (Acouson Sequoia C 256 with a 2.5-3.5 probe) was used to rule out the presence of turbulent flow or thrombi, to evaluate the presence of atrioventricular valve(s) incompetence, and to assess the ejection fraction at rest in the four chamber view.

Transoesophageal atrial stimulation was performed, under mild sedation, according to the protocol described previously. ${ }^{15}$ The following parameters were evaluated: firstly, corrected atrial recovery time, used as an expression of sinus node function; secondly, the heart rate at which Luciani Wenckebach $2^{\circ}$ atrioventricular block appeared during asynchronous atrial stimulation; and lastly, inducibility of re-entry atrial tachycardia.

Ergometric test was performed on a stationary cycle, following the protocol of James and colleagues. ${ }^{16}$ The following parameters were evaluated: maximal work load, maximal heart rate and blood pressure, minute ventilation, maximum oxygen consumption, and ventilatory anaerobic threshold. Patients were classified in accordance with the Weber functional class. ${ }^{17}$

Multiple gated equilibrium radionuclide angiography was performed with the subject in the semiorthostatic position on the stress table. Every three minutes the work load was increased by $25 \mathrm{~W}$ until maximum exercise was reached or symptoms appeared. If patients became exhausted before completing the test, the work load was reduced by $25 \mathrm{~W}$ to allow acquisition for at least two minutes. Heart rate, blood pressure, and ECG were monitored throughout the exercise. Ejection fraction was calculated after background subtraction by interactive semiautomated software. The normal value for ejection fraction at rest was $\geqslant 50 \%$. An increase of $\geqslant 5 \%$ of resting ejection fraction was considered to be a normal response to exercise, and a decrease of $\geqslant 5 \%$ was considered to indicate exercise dysfunction. A single operator processed all the studies.

\section{RESULTS}

\section{Operative results}

Table 3 shows the perioperative data. Mean (SD) duration of extracorporeal circulation and aortic cross clamp was 6 (1.7) hours and 35.4 (25.5) minutes, respectively. Mean (SD) duration of mechanical ventilation was 3.5 (3.5) days. Mean (SD) intensive care unit and hospital stay was 5.9 (4.8) and 22 (6.7) days, respectively.

Early complications were one transient low output syndrome and one limb ischaemia, requiring left tight fasciotomy. One hospital death occurred as a result of pneumonia 11 days after intervention.

At discharge all patients were in NYHA class I or II. ECGs showed sinus rhythm in four patients and paced rhythm in six. One late complication was observed in patient 8 , in whom, because of poor control of anticoagulation, a thrombus at the junction of the inferior vena cava and the hepatic veins, successfully treated with heparin infusion, was observed two months after reconversion.

Table 4 Follow up data

\begin{tabular}{|c|c|c|c|c|c|c|c|}
\hline \multirow[b]{2}{*}{ Patient } & \multirow[b]{2}{*}{ NHYA class } & \multirow[b]{2}{*}{ Basal rhythm } & \multirow{2}{*}{$\begin{array}{l}\text { Relapse of } \\
\text { arrhythmia }\end{array}$} & \multicolumn{4}{|c|}{ Transoesophageal stimulation } \\
\hline & & & & cSNRT (ms) & W point & $\operatorname{RAP}(\mathrm{ms})$ & Induction of SVT \\
\hline 1 & 1 & SR & No & 520 & 160 & 280 & No \\
\hline 2 & I & SR & No & 240 & 220 & 230 & No \\
\hline 3 & 1 & PM & AT & & & & No \\
\hline 4 & 1 & SR & No & 220 & 200 & 240 & No \\
\hline 6 & i & SR/PM & No & $1800 *$ & 220 & 200 & No \\
\hline 7 & 1 & SR/PM & AT & & & & No \\
\hline 8 & 1 & $\mathrm{SR} / \mathrm{PM}$ & AT & 140 & 180 & $340 *$ & No \\
\hline 9 & ॥ & SR/PM & No & & & & No \\
\hline 10 & 1 & $\mathrm{SR} / \mathrm{PM}$ & No & 540 * & 150 & 340 * & No \\
\hline 11 & I & $P M$ & No & & & & No \\
\hline
\end{tabular}

AT, atrial tachycardia; cSNRT, corrected sinus node recovery time; RAP, refractory atrial period; SVT, supraventricular tachycardia; W point, Wenckebach point. *Exceeds normal limit. 
Table 5 Ergometric test results

\begin{tabular}{|c|c|c|c|c|c|c|c|c|c|c|c|c|}
\hline Patient & $\begin{array}{l}\text { Work } \\
\text { load (W) }\end{array}$ & $\begin{array}{l}\text { Basal } \\
\text { rhythm }\end{array}$ & $\begin{array}{l}\text { Rhythm } \\
\text { on effort }\end{array}$ & $\begin{array}{l}\text { Maximum } \\
\text { heart rate } \\
\text { (beats/min) }\end{array}$ & $\begin{array}{l}\text { Maximum } \\
\text { systemic BP } \\
(\mathrm{mm} \mathrm{Hg})\end{array}$ & $\begin{array}{l}\text { VE } \\
(\mathrm{I} / \mathrm{min})\end{array}$ & $\begin{array}{l}\% \text { of } \\
\text { predicted } \\
\text { value }\end{array}$ & $\begin{array}{l}\mathrm{AT} \\
\left(\mathrm{Vo}_{2} / \mathrm{ml} /\right. \\
\mathrm{kg} / \mathrm{min})\end{array}$ & $\begin{array}{l}\text { Maximum } \\
\mathrm{VO}_{2}\end{array}$ & $\begin{array}{l}\% \text { of } \\
\text { predicted } \\
\text { value }\end{array}$ & $\begin{array}{l}\text { Weber } \\
\text { class }\end{array}$ & $\begin{array}{l}\mathrm{VCO}_{2}: \mathrm{VO}_{2} \\
\text { ratio }\end{array}$ \\
\hline 1 & 105 & SR & SR & 99 & 140 & 40.9 & 47 & 8.8 & 14.2 & 31 & C & 1.1 \\
\hline 2 & 120 & SR & SR & 147 & 140 & 52.7 & 86 & 14.4 & 21.2 & 56 & A & 1.2 \\
\hline 3 & 128 & PM & $P M$ & 123 & 100 & 19.8 & 36 & 4 & 9 & 27 & C & 0.97 \\
\hline 4 & 165 & SR & SR & 160 & 120 & 36.3 & 64 & 11.2 & 16.6 & 50 & C & 1.1 \\
\hline 6 & 95 & SR & SR & 116 & 120 & 34.3 & 68 & 9.6 & 17.5 & 54 & B & 0.99 \\
\hline 7 & 66 & SR & PM & 110 & 140 & 41.1 & 67 & 11.5 & 15.2 & 36 & C & 1.01 \\
\hline 8 & 72 & SR & $S R$ & 170 & 140 & 30.2 & 51 & 8.1 & 11.1 & 33 & C & 1.16 \\
\hline 9 & 120 & SR & PM & 93 & 125 & 52.9 & 67 & 16.2 & 17.4 & 43 & C & 1.07 \\
\hline 10 & 90 & PM & $P M$ & 160 & 150 & 58.0 & 69 & 9.6 & 13.7 & 28 & C & 1.1 \\
\hline
\end{tabular}

$\mathrm{AT}$, anaerobic threshold; $\mathrm{BP}$, blood pressure; $\mathrm{VCO}_{2}$, carbon dioxide production; $\mathrm{VE}$, minute ventilation; $\mathrm{VO}_{2}$, oxygen consumption.

\section{Follow up}

Mean (SD) duration of follow up was 16.8 (5.6) months. Relapse of atrial tachycardia occurred in three patients 11,3 , and 6 months after reintervention and was controlled with medical treatment. In patient 7 , because of coexistent atrial tachycardia and bradycardia, a pacemaker generator was implanted 11 months after total cavopulmonary connection and medical treatment was started, with complete control of the arrhythmia. In all the remaining patients Holter registration did not show any arrhythmia. All patients were treated with antiaggregating or anticoagulating agents. Three patients $(7,8$, and 11$)$ with suboptimal ventricular function were prescribed vasodilators and diuretics.

Echocardiography showed a mean (SD) ejection fraction of $48.9(11.2) \%$, being $<50 \%$ in two patients and $>40 \%$ in one. A mild incompetence of the atrioventricular valve was present in four patients $(2,4,6$, and 9). All patients had laminar flow in the systemic venous conduit, without a smoke-like effect.

Table 4 shows the results of transoesophageal atrial stimulation. It was performed in all but two patients (patient 3 had recent relapse of atrial tachycardia and patient 9 declined to collaborate). Atrial recovery time was detectable in only six patients who were not paced and was prolonged in two. Atrioventricular conduction was normal in all patients; Luciani Wenckebach $2^{\circ}$ atrioventricular block appeared at a mean (SD) heart rate of 188.3 (29.9) beats/min. Supraventricular tachycardia was not induced in any patients.

Table 5 shows the results of ergometric tests. At rest seven patients were in sinus rhythm and two were paced. On effort four were paced. The mean (SD) maximal work load, heart rate, and blood pressure were 106 (31) W, 131 (29) beats/min, and 130 (16) $\mathrm{mm} \mathrm{Hg}$, respectively. Mean (SD) minute ventilation was 40 (12) litres/min, corresponding to 61.7 (14.7)\% of the predicted value, and mean (SD) maximum oxygen uptake was 15.1 (3.7) litres/min, corresponding to 39.8 (11.3)\% of the predicted value. Anaerobic threshold was reached in all cases, with a mean (SD) rate of $10.4(3.6) \mathrm{ml} / \mathrm{kg} / \mathrm{min}$.
Myocardial scintigraphy (table 6) showed an improvement of myocardial performance either at rest or on effort but it did not reach significance. Mean basal ejection fraction increased from $39.4 \%$ (95\% confidence interval (CI) $32 \%$ to $46 \%$ ) to $46.5 \%$ (95\% CI $41.7 \%$ to $51.2 \%$ ), and ejection fraction on effort increased from $42.3 \%$ (95\% CI $33.9 \%$ to $50.7 \%$ ) to $50.2 \%$ (95\% CI $44.5 \%$ to $55.9 \%$ ). The mean increment of ejection fraction on effort varied from $8.2 \%$ (95\% CI $8.1 \%$ to $24.3 \%$ ) to $10.9 \%$ ( $95 \%$ CI $14.5 \%$ to $23.8 \%$ ). Preoperatively ventricular dysfunction at rest and on effort was found in nine and five patients, respectively. Postoperatively ventricular dysfunction at rest and on effort was found in five and two patients, respectively. Thus, ventricular dysfunction at rest was reversed in three patients and dysfunction on effort in four.

\section{DISCUSSION}

Total cavopulmonary anastomosis was introduced with the aim of reducing the late complications usually observed in patients with atriopulmonary Fontan, such as giant right atrium, refractory or debilitating arrhythmias, pulmonary venous obstruction, ventricular dysfunction, and protein losing enteropathy. ${ }^{12} 1819$ In some patients these complications can be controlled with anticoagulating, anticongestive, and antiarrhythmic drugs or with radiofrequency ablation. More often myocardial dysfunction caused by coronary sinus hypertension," pulmonary venous compression caused by giant right atrium, atrial arrhythmias caused by previous suture lines, and right atrial enlargement are difficult to manage medically. In the past, these patients usually underwent cardiac transplantation.

The extracardiac conduit approach excludes the right atrium from the systemic venous circuit, avoids additional atrial suture lines, and allows extensive atrioplasty, with removal of arrhythmogenic atrial tissue. At the time of total cavopulmonary connection, some authors have suggested that arrhythmia circuit cryoablation be performed and an antitachycardia pacemaker be implanted. ${ }^{12}$ Studies of relatively

Table 6 Scintigraphic data

\begin{tabular}{|c|c|c|c|c|c|c|}
\hline \multirow[b]{2}{*}{ Patient } & \multicolumn{3}{|c|}{ Preoperative data } & \multicolumn{3}{|c|}{ Postoperative data } \\
\hline & EF at rest (\%) & EF on effort (\%) & Variation (\%) & EF at rest (\%) & EF on effort (\%) & Variation (\%) \\
\hline 1 & 47 & 61 & +30 & 53 & 58 & +9 \\
\hline 2 & 32 & 42 & +31 & 50 & 62 & +24 \\
\hline 3 & 42 & 35 & -17 & 42 & 44 & +4 \\
\hline 4 & 37 & 38 & +2 & 41 & 49 & +19 \\
\hline 5 & 38 & 40 & +5 & NA & NA & NA \\
\hline 6 & 27 & 38 & +40 & 45 & 54 & +20 \\
\hline 7 & 30 & 20 & -33 & 41 & 44 & +7 \\
\hline 8 & 60 & 59 & +2 & 54 & 40 & -26 \\
\hline 9 & NA & NA & NA & 54 & NA & NA \\
\hline 10 & 43 & 45 & +4 & 35 & 46 & +31 \\
\hline 11 & 38 & 45 & +18 & 50 & 55 & +10 \\
\hline
\end{tabular}


small numbers of patients ${ }^{12}{ }^{13} 20$ showed that conversion of atriopulmonary Fontan has favourable results in terms of improvement of the functional class, reversion of protein losing enteropathy, and control of arrhythmias. However, when antiarrhythmic procedures were not performed, the relapse of unresponsive atrial tachycardia was frequent and, occasionally, required heart transplantation. ${ }^{13}$

Our data show that conversion of atriopulmonary to total cavopulmonary connection, in accordance with other authors' reports, ${ }^{7213}$ has a relatively low mortality and morbidity. Although, before reintervention, none of our patients was in a functional class higher than III, at a mean follow up of 17 months all but one were in class I. Previous data showed that patients in class IV can also improve, after reconversion, to class I-II. ${ }^{12}{ }^{13}$

We confirmed that intra-atrial tachycardia frequently occurs in Fontan patients. Its anatomical substrates are scars, patches, fibrotic areas related to atrial dilatation, and natural barriers such as the atrioventricular valves, and the orifices of the venae cavae and of the pulmonary veins. In this setting, we performed a compartmentalisation of the right atrium, as suggested by Mavroudis and colleagues. ${ }^{12}$ As this arrhythmia may be caused by a macro re-entry or to a micro re-entry circuit, an extensive right atrial wall resection seemed ideal to reduce the occurrence of micro re-entry circuits. Ablative procedures have been performed without a preoperative electrophysiological evaluation. The increasing experience with atrial arrhythmias, obtained with percutaneous ablative procedures, improved the understanding of the correlations between the electrocardiographic patterns and the anatomical substrate of arrhythmias, reducing the number of diagnostic electrophysiological studies. Concerns may be raised for intra-atrial re-entry tachycardia, in which this correlation is usually lacking, because of the coexistence, in the same patient, of multiple sites in which re-entry circuits can develop. However, when a surgical ablative procedure is planned, every effort should be made to ablate all possible re-entrant circuits and, for this purpose, a preoperative electrophysiological evaluation was not considered to be essential.

Our data confirm that reconversion of atriopulmonary to total cavopulmonary connection provides better control of arrhythmias, allowing antiarrhythmic treatment to be stopped in about $50 \%$ of patients. Relapse of arrhythmias, easily controlled by reintroduction of medical treatment, was observed in $30 \%$ of patients. No further relapse of arrhythmia was observed after the reintroduction of medical treatment. In the setting of Fontan reconversion relapse of atrial arrhythmia has multiple explanations. Firstly, not all right atrial tissue can be removed. Secondly, new suture lines are necessarily created. Thirdly, gaps in a linear lesion are created by cryoablation and, less frequently, by radiofrequency ablation. In terms of relapse of arrhythmias, radiofrequency ablation is theoretically superior to cryoablation, as with this technique it is more difficult to leave gaps in a linear lesion. In addition, radiofrequency ablation is less time consuming than cryoablation. However, in our series, we applied cryoablation in six patients and radiofrequency ablation in five, and observed relapse of arrhythmias in both groups. The most important complication of intraoperative ablation was sinus node dysfunction. Sinus node dysfunction was probably caused in part by the extensive atrial wall reduction and in part by ablation lines placed near the sinus node. Sinus node dysfunction may be present immediately after discontinuation of bypass but may appear later, as in two of our patients who developed sick sinus syndrome after one and 24 months, respectively. According to our results, an atrial wire should be inserted in every patient undergoing Fontan conversion even if sinus rhythm is present at the end of the operation. Transoesophageal atrial stimulation confirmed the good early results of intraoperative ablation, as no patient had inducible atrial arrhythmia. On the contrary, sinus node dysfunction was present in most patients, as two had a permanent AAIR pacemaker rhythm and three had a low heart rate increment during the stress test. In our patients atrial wall reduction and ablative lesions close to the sinus node probably worsened the sinus node dysfunction, often present in Fontan patients. These observations reinforce the need for implanting an atrial epicardial wire during reoperation, with the aim of preserving atrial contraction and optimising ventricular function.

Ergometric test data, available in only two patients before conversion, did not allow the evaluation of a possible improvement of exercise capacity after reconversion. All our patients were able to perform a significant test, reaching the anaerobic threshold. All but two had a poor exercise tolerance. This is in accordance with previous data showing that Fontan patients have a decreased exercise tolerance, ${ }^{2021}$ a reduced peak and mean maximal oxygen uptake, and prolonged recovery time for heart rate and maximum oxygen uptake..$^{21}$ This response to exercise has been attributed to a reduction in stroke volume at both low and high intensity exercise, to an abnormal linkage of ventilation to tissue carbon dioxide production, and to an increased dependence on anaerobic metabolism in skeletal muscles. ${ }^{21}$ In most patients the increment of heart rate during effort was very low, suggesting a latent sinus dysfunction.

Previous studies of ventricular function after Fontan operation found an abnormal systolic function and a depressed response to exercise in most patients. ${ }^{23}$ Ventricular filling abnormalities have been found to be common after atriopulmonary anastomosis, regardless of the type of dominant ventricular morphology, and are thought to be related to either intrinsic myocardial or acquired factors, such as an increased mass to volume ratio and raised systemic vascular resistances. ${ }^{24}{ }^{25}$ Our data confirm a depressed ventricular function either at rest or on effort in Fontan patients, whereas they show an improvement in myocardial performance after reconversion in most of them. Previous data on scintigraphic evaluation of ventricular function before and after repeat Fontan operation are not available. The observed improvement in myocardial function after reconversion may be attributed to reversion of the hypertension in the coronary sinus and subsequent improvement of coronary perfusion, to reversion of pulmonary vein compressions, to removal of the atrial reservoir, and to restoration of laminar systemic venous flow. In addition, the preservation of the spontaneous or paced sinus rhythm, maintaining the synchronism between atrial and ventricular contraction, may optimise the function of the single ventricle.

In conclusion, conversion from atriopulmonary to total cavopulmonary connection can constitute an alternative to cardiac transplantation in patients with atriopulmonary connection with uncontrolled arrhythmias, ventricular dysfunction, or obstruction of the conduit. A longer follow up is required to test the incidence of arrhythmia relapse and the durability of the improvement of ventricular function and functional class.

\section{Authors' affiliations}

G Agnoletti, A Borghi, Divisione di Cardiologia, Ospedali Riuniti, Bergamo, Italy

GC Crupi, Divisione di Cardiochirurgia, Ospedali Riuniti, Bergamo, Italy G Vignati, Divisione di Cardiologia Pediatrica, Ospedale Niguarda, Milan, Italy

\section{REFERENCES}

1 Fontan F, Baudet E. Surgical repair of tricuspid atresia. Thorax 1971;26:240-8

2 Kreutzer G, Galindez E, Bono H, et al. An operation for the correction of tricuspid atresia. J Thorac Cardiovasc Surg 1973;66:613-21.

3 Puga FJ, Chiavarelli M, Hagler DJ. Modifications of the Fontan operation applicable to patients with left atrioventricular valve atresia or single atrioventricular valve. Circulation 1987;76(suppl):III53-60. 
4 De Leval MR, Kilner P, Gewillig M, et al. Total cavopulmonary connection: a logical alternative to atriopulmonary connection for complex Fontan operations: experimental studies and early clinical experience. J Thorac Cardiovasc Surg 1988;96:682-95.

5 Bridges ND, Lock JE, Castaneda AR. Baffle fenestration with subsequent transcatheter closure: modification of the Fontan operation for patients at increased risk. Circulation 1990;82:1681-9.

6 Marcelletti C, Corno A, Giannico S, et al. Inferior vena cava-pulmonary artery extracardiac conduit: a new form of right heart bypass. J Thorac Cardiovasc Surg 1990;100:228-32.

7 Conte S, Gewillig M, Eyskens B, et al. Management of late complications after classic Fontan procedure by conversion to total cavopulmonary connection. Cardiovasc Surg 1999;7:651-5.

8 Peters NS, Somerville J. Arrhythmias after the Fontan procedure. Br Heart J 1992;68: 199-204.

9 Miura T, Hiramatsu T, Forbess JM, et al. Effects of elevated coronary sinus pressure on coronary blood flow and left ventricular function: implications after the Fontan operation. Circulation 1995 92(suppl)::I1298-303

10 Kao JM, Alejos JC, Grant PW, et al. Conversion of atriopulmonary to cavopulmonary anastomosis in management of late arrhythmias and atrial thrombosis. Ann Thorac Surg 1994;58:1510-4.

11 Ilbawi MN, Idriss FS, Muster A, et al. Effects of elevated coronary sinus pressure on left ventricular function after the Fontan operation. An experimental and clinical correlation. J Thorac Cardiovasc Surg 1986:92:231-7.

12 Mavroudis C, Backer CL, Deal BJ, et al. Fontan conversion to total cavopulmonary connection and arrhythmia circuit cryoablation. J Thorac Cardiovasc Surg 1998;115:547-56.

13 Marcelletti CF, Hanley FL, Mavroudis C, et al. Revision of previous Fontan connections to total extracardiac cavopulmonary anasatomosis: a multicenter experience. J Thorac Cardiovasc Surg 2000; 1 19:340-6.

14 Hoyer MH, Beerman LB, Ettedguis JA, et al. Transatrial lead placement for endocardial pacing in children. Ann Thorac Surg 1994;58:97-101.
15 Vignati G, Mauri L, Lunati $M$, et al. Transesophageal electrophysiological evaluation of pediatric patients with Wolff-Parkinson-White syndrome. Eur Heart J 1992;13:220-2.

16 James F, Kaplan S, Glueck C, et al. Responses of normal children and young adults to controlled bicycle exercise. Circulation 1980:61:902-12

17 Weber KT, Kinasewitz GT, Janicki JS, et al. Oxygen utilization and ventilation during exercise in patients with chronic cardiac failure. Circulation 1982;65:1213-23

18 Vitullo DA, DeLeon SY, Berry TE. Clinical improvement after revision in Fontan patients. Ann Thorac Surg 1996:61:1787-804.

19 McElhinney DB, Reddy VM, Moore P, et al. Revision of previous Fontan connections to extracardiac or intraatrial conduit cavopulmonary anastomosis. Ann Thorac Surg 1996;62:1276-83.

20 Iserin L, Chua TP, Chambers J, et al. Dyspnoea and exercise intolerance during cardiopulmonary exercise testing in patients with univentricular heart. The effects of chronic hypoxaemia and Fontan procedure. Eur Heart J 1997; 18:1350-6.

21 Troutman WB, Barstow TJ, Galindo AJ, et al. Abnormal cardiorespiratory responses to exercise in paediatric patients after Fontan procedure. J Am Coll Cardiol 1998;31:668-73.

22 Mocellin R, Gildein P. Velocity of oxygen uptake response at the onset of exercise: a comparison between children after cardiac surgery and healthy boys. Pediatr Cardiol 1999;20:17-20.

23 Hurwitz RA, Caldwell RL, Girod DA, et al. Left ventricular function in tricuspid atresia: a radionuclide study. J Am Coll Cardiol 1986;11:916-21

24 Akagi T, Benson LN, Green M, et al. Ventricular performance before and after Fontan repair for univentricular atrioventricular connection: angiographic and radionuclide assessment. J Am Coll Cardiol 1992:20:920-6.

25 Akagi T, Benson LN, Gilday DL, et al. Influence of ventricular morphology on diastolic filling performance in double inlet ventricle after the Fontan procedure. J Am Coll Cardiol 1993:22:1948-52.

\section{IMAGES IN CARDIOLOGY}

\section{Vasospastic angina}

A

50 year old woman was admitted with central crushing chest pain. She had a trong family history of ischaemic heart disease (IHD). Her cholesterol was $4.7 \mathrm{mmol} / \mathrm{l}$. There were no other risk factors for IHD. At the time of admission she was haemodynamically stable. Her ECG showed 2-6 mm ST segment elevation in the inferior leads. She was thrombolysed with tenecteplase. The ECG showed complete resolution of the ST segment. There was no elevation of cardiac troponin. She developed further chest pain with ST segment elevation in the inferior leads, and coronary angiography showed complete occlusion of the proximal right coronary artery (upper panel, middle). A prophylactic temporary pacemaker was inserted because the patient developed severe sinus bradycardia. This lesion did not respond to intracoronary nitrates. Hence the lesion was predilated and stented (Guidant Penta 4/38) with a good result angiographically (lower panel, middle). Twenty four hours later the patient developed further chest pain and ST segment elevation in the inferior leads. Repeat coronary angiography showed the stent was widely patent but there was a severe diffuse coronary artery spasm distal to the stent (upper panel, right) which responded very well with intracoronary nitrates (lower panel, right)

We believe that the complete occlusion of the right coronary artery initially was probably caused by severe coronary artery spasm which was resistant to intracoronary nitrates. The patient was discharged on maximal dose of calcium channel blockers and nitrates. She still has recurrent chest pain and a recent angiogram showed mild spasm of the proxi-
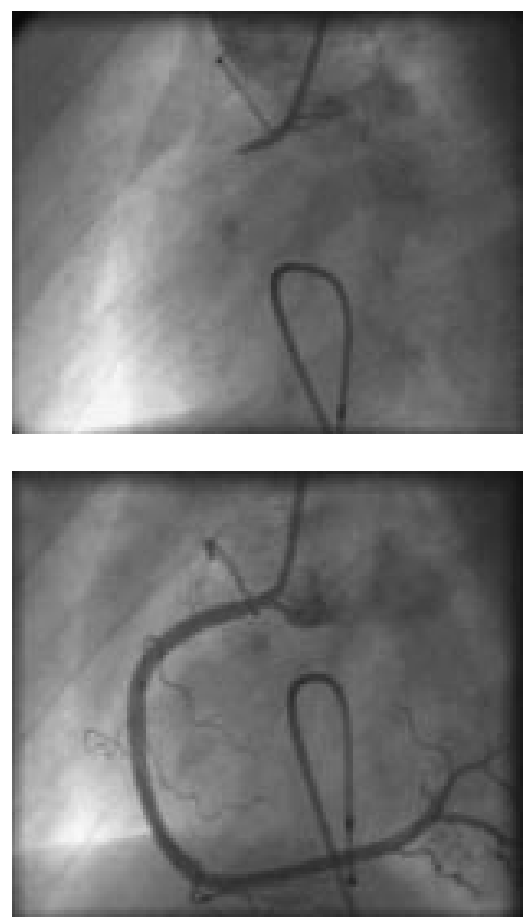

mal coronary artery just proximal to the origin of the stent, which responded to intracoronary nitrates.

V Suresh
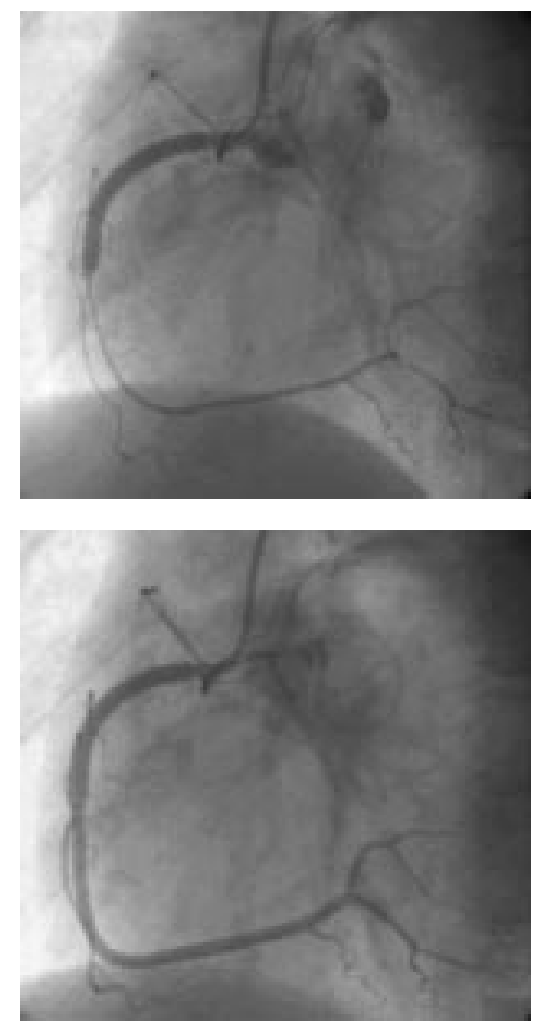

Sureshpriya2000@yahoo.com 